\title{
INVERSE RELATION BETWEEN LEUCOCYTE COUNT AND CARDIAC VAGAL FUNCTION IN PATIENTS WITH HYPERTENSION
}

Ng. Javan, Rolinda Rajkumari, Joshna Thiyam, Susie Keithellakpam, Khumallambam Ibomcha Singh

1. Assistant Professor. Department of Surgery, Jawaharlal Nehru Institute of Medical Sciences, Porompat, Imphal, Manipur, India.

2. Assistant Professor. Department of Physiology, Jawaharlal Nehru Institute of Medical Sciences, Porompat, Imphal, Manipur, India.

3. Assistant Professor. Department of Physiology, Jawaharlal Nehru Institute of Medical Sciences, Porompat, Imphal, Manipur, India.

4. Demonstrator. Department of Physiology, Jawaharlal Nehru Institute of Medical Sciences, Porompat, Imphal, Manipur, India.

5. Senior Resident. Department of Surgery, Jawaharlal Nehru Institute of Medical Sciences, Porompat, Imphal, Manipur, India.

\section{CORRESPONDING AUTHOR:}

Dr. Rolinda Rajkumari

Assistant Professor

Department of Physiology,

Jawaharlal Nehru Institute of Medical Sciences,

Porompat, Imphal - 795005 Manipur, India.

E-mail: rolinda_rk65@rediffmail.com

ABSTRACT: Inflammation has been implicated in the pathophysiology of hypertension; and total leucocyte count as well as C-reactive protein is elevated in patients with hypertension. Reduced vagal activity has been reported to predict cardiovascular events such as mortality in patients with hypertension. The aim of this study was to investigate the possible correlation between cardiac vagal function and total leucocyte count in the patients with hypertension. Thirty-five patients with hypertension and 35 age - and sex -matched healthy controls were examined. Vagal function was estimated by resting heart rate variability (HRV), expiratory: inspiratory ratio (E: I ratio) and basal heart rate from lead II of ECG using Student's physiograph. The total leucocyte count (TLC) was counted in the improved Neubauer's chamber under light microscope. Statistical analysis was done using Student's unpaired t test for comparisons and Pearson correlation for significant association. The results show a statistically significant reduction in the resting HRV $(\mathrm{p}<0.01)$, E: I ratio $(\mathrm{p}<0.05)$, increased TLC $(\mathrm{p}<0.01)$ and increased resting minimum heart rate $(\mathrm{p}<0.01)$ in patients with hypertension as compared to controls. The resting maximum heart rate showed no statistical differences between the patients and the controls. An inverse relation between TLC and vagal function (resting HRV, $\mathrm{p}<0.05$; E:I ratio, $\mathrm{p}<0.05$ ) in patients with hypertension was observed. Our result indicates that an increased TLC level is significantly associated with reduced basal HRV and E:I ratio in patients with hypertension. It is possible that the vagus function and inflammation could interact with each other resulting in the progression of hypertension.

KEY WORDS: Expiratory: Inspiratory ratio, Heart rate variability, Inflammation, Total leucocyte count, Vagal function

INTRODUCTION: Hypertension is a major contributor to the cardiovascular morbidity and mortality in industrialized countries. It is also rapidly increasing in the developing countries like 
India. In 2000, it was estimated that 118 million population in India will have hypertension and the number is predicted to almost double to 214 million in $2025 .{ }^{1}$ Hypertension is directly responsible for $57 \%$ of all stroke and $24 \%$ of coronary heart disease deaths in India. ${ }^{2}$

Autonomic nervous system plays an important role in the regulation of blood pressure (BP) and a large proportion of patients with hypertension are found to have increased sympathetic and decreased vagal activity. Reduction in vagal tone is also found to be associated with mortality and major adverse cardiovascular events in patients with hypertension. ${ }^{3}$

Recently, inflammation has been speculated as one of the mechanism in the development of hypertension. Cross-sectional evidence demonstrates elevation of inflammatory markers such as interleukin-6 and C-reactive proteins (CRP) level among individuals with high blood pressure. ${ }^{4}$ It has also been reported that elevated white blood cell (WBC) count predicted an increased incidence of hypertension among Japanese population. ${ }^{5}$ In addition, higher WBC count is associated with impaired endothelial-induced vasodilation and hence to the development and progress of the hypertension. ${ }^{6}$ Several studies have shown a relationship between autonomic dysfunction and activation of the inflammatory system in heart diseases. 7,8 The present study was conducted to evaluate any possible correlation between vagal function and total leucocyte count in the patients with hypertension.

MATERIAL AND METHODS: The present study was conducted on 35 patients of hypertension. The age group of the patients was between 30-65 years. Among the patients, 20 were males and 15 were females. Patients who were willing to undergo investigation were recruited from Outpatient Department of Surgery, Jawaharlal Nehru Institute of Medical Sciences, Imphal after which they were sent to the Department of Physiology for various tests. Hypertension was defined as systolic blood pressure $\geq 140 \mathrm{mmHg}$ and /or diastolic blood pressure $\geq 90 \mathrm{mmHg}$ and /or use of antihypertensive drugs. Exclusive criteria included patients with coronary heart disease, nephropathy, diabetes mellitus, any infection, receiving steroids or immunosuppressive drugs in the past, smoking and pregnant women.

Thirty five healthy controls age- and sex- matched were taken. They were healthy as reported by history, physical examination, and none of them were on medication (selfreported). The research was carried out after taking the clearance from the ethical committee of the Institution. All the participants were explained about the study in details and their written informed consents were taken.

Blood pressure: Three blood pressure (BP) recordings at an interval of 2 minutes were taken after the patient was made to sit for 30 minutes with the standard mercury sphygmomanometer in the left arm. The first appearance of the sound and disappearance of the sound were taken as systolic BP and diastolic BP respectively.

Blood examination: One $\mathrm{ml}$ of venous blood was drawn into EDTA containing vial. The total leucocyte count was done using 0.5 part of blood mixed with 10 part of Turk's fluid followed by counting of leucocyte in the counting chamber (improved Neubauer's chamber) under light microscope.

Resting heart rate variability: It was calculated from lead II of ECG using Student's physiograph. The lead II was recorded for 1 minute. Then the minimum and maximum R-R 
interval were identified and converted into heart rate (HR). The difference of the maximum HR and the minimum HR give the heart rate variability in one minute.

E:I (expiratory: inspiratory) ratio: Heart rate during the deep and regular breathing at the rate of 6 breaths per minutes (i.e. each cycle consisting of 5 seconds of inspiration followed by 5 seconds of expiration) was recorded from lead II of ECG. The E:I ratio was calculated as the ratio of the longest R-R interval and shortest R-R interval averaged over 6 cycles.

Statistical analysis: It was done using SPSS 13.0. All the values were expressed as mean \pm SD. Comparisons between the patients with hypertension and the controls were performed using Students "unpaired t test". The Pearson correlation analysis was used to test for significant association between the vagal tests (resting heart rate, E: I ratio and resting heart rate variability) and total leucocyte count in patients with hypertension. Statistical significance was considered to be present when the two-tailed probability was less than 0.05

RESULTS: Table 1 shows comparison of average age, body mass index, blood pressure, resting heart rate, resting heart rate variability and E:I ratio between the patients with hypertension and the controls. The average systolic and diastolic BP of the patients with hypertension were $142.94 \pm 7.58 \mathrm{mmHg}$ and $91.65 \pm 5.1 \mathrm{mmHg}$ respectively while that of the controls were $115.71 \pm 7.45$ and $72.34 \pm 8.56$ respectively. The average age, height, weight, body mass index showed no significant differences between them. The resting heart rate variability $(\mathrm{p}<0.01)$ and E:I ratio $(p<0.05)$ were lower in the patients with hypertension which were statistically significant. The total leucocyte count $(\mathrm{p}<0.01)$ and resting minimum heart rate $(\mathrm{p}<0.01)$ were significantly higher in the patients with hypertension than the controls. The resting maximum heart rate was higher in the patients with hypertension which was not significant.

Table 2 shows the relation between total leucocyte count and vagal tests in patients with hypertension. An inverse relation between total leucocyte count and resting heart rate variability $(\mathrm{r}=-0.346, \mathrm{p}<0.05)$ and E:I ratio $(\mathrm{r}=-0.343, \mathrm{p}<0.05)$ were observed. However, there was no significant relation found between the resting heart rate and total leucocyte count.

DISCUSSION: The result of the present study demonstrates an inverse relationship between total leucocyte count (TLC) and the vagal function in patients with hypertension (table 2). Sajadieh et al ${ }^{9}$ have reported that reduced heart rate variability (HRV) was related to white blood cell and CRP concentration when taken as markers of inflammation in the middle-aged to elderly healthy white population suggesting the involvement of an imbalance of the autonomic nervous system in the inflammatory reaction and the interaction might play an important role in the development of cardiovascular disease. In another study conducted by Kon et al 10, they have revealed an association between parasympathetic nerve withdrawal and inflammation in middle-aged to elderly Japanese general population. They thought that autonomic nervous system and inflammation may interact and thus may be involved in the progression of cardiovascular disease. But, Psychari et al ${ }^{8}$ have failed to show any relation between CRP (inflammatory marker) and parasympathetic mediated indices of rMSSD and pNN50 in patients with post-myocardial infarction. However, they could not rule out completely the involvement of parasympathetic activity because LF (low frequency) and TP (total power) component of HRV, which have been used as indexes of sympathetic and parasympathetic component have shown the inverse relation with CRP 
The reasons for the association between the TLC and vagal function remain unknown from this study. However, an interaction between the autonomic nervous system and the immune system has been reported. Experimentally, both exposure to acetylcholine and direct vagal stimulation inhibits release of cytokines by macrophages while sympathetic activation is pro-inflammatory. ${ }^{11}$ Cytokines, secreted by leucocytes, are known to act on the nervous system.12 In fact, certain cytokines activate both autonomic nervous system and the hypothalamic-pituitary-adrenal axis or vice-versa. ${ }^{13}$ Tracey et al 14 have shown that both electrical and pharmacological stimulation of the efferent vagal nerve decreases levels of circulating cytokines. Conversely, withdrawal of the parasympathetic nerve activity may facilitate inflammatory reaction. Inflammation increases oxidative stress, which may lead to inactivation of nitric oxide, a substance known to modulate vasodilation, enhance vagal tone and autonomic control in the sinus as well as atrioventricular node in humans.15,16 In disease like ankylosing spondylitis, markers of inflammation have been found to be related to abnormal autonomic tone. 17

Our results show lower vagal function (reduced E:I ratio and resting HRV; table 1) in patients with hypertension than the healthy controls. Pavithran et al 18 have reported a diminished short-term HRV as well as heart rate variation during deep breathing in patients with new-onset of hypertension. They suggested that the diminished HRV is due to imbalance of cardiovascular autonomic function. Neumann et al ${ }^{19}$ have revealed that both persistent and white coat hypertension has shown reduced high frequency (HF) power of HRV compared to normotensive subjects reflecting attenuated vagal control of the heart. The decrease in vagal activity in patients with hypertension observed in our study could be due to impairment of baroreflex secondary to structural changes in carotid sinus and aortic sinus resulting from hyperkinetic flow of blood in hypertensive patients. In a previous study by Demirci et al ${ }^{20}$, it has been shown that carotid arterial stenting is associated with a short-term parasympathetic predominance that was associated with decreased BP. Also impairment of baroreflex sensitivity caused by hypertension is mainly due to reduced maximum capacity of the cardiac vagal component rather than to a change in the sympathetic component. ${ }^{21}$ Nemes et al ${ }^{22}$ have reported that in healthy individuals there is a negative correlation between heart rate response to deep breathing and aortic stiffness; and a positive with distensibility, though, their study did not show any relation between sympathetic function and aortic stiffness.

The present study also reveals an elevated total leucocyte count (TLC) in patient with hypertension as compared to the healthy controls. The association of high leucocyte count with the incidence of hypertension in Japanese women has been reported. ${ }^{5}$ It is suggested from the animal study that elevated levels of glucocorticoid in hypertensive rats inhibits the p-selectin mediated leucocyte endothelial cell interaction resulting in the reduction of the margination of the leucocyte thereby increasing the circulating leucocyte count. ${ }^{23}$ Higher white blood cell count is also inversely related to acetylcholine-induced endothelial dilation of the vessels in patients with hypertension, diabetes mellitus and healthy adults.6,24

CONCLUSION: The result of the present study indicates that an increased TLC level is significantly associated with reduced resting HRV and E: I ratio in patients with hypertension. It is possible that the reduced vagus function and inflammation could interact with each other resulting in the progression of hypertension. 
Shortcomings of this study: There are shortcomings in this study like any other studies. Firstly, the sample size is relatively small and larger population should be considered in future study. Secondly, our study is not able to explain the reason of the inverse relation between the TLC and reduced vagal activity in hypertensive patients. However, previous studies have postulated that certain cytokines activate both autonomic nervous system and the hypothalamic-pituitary-adrenal axis or vice-versa. Whether interventions that augment vagal activity or control inflammation would benefit patients with hypertension draws the attention of further studies.

ACKNOWLEDGEMENTS: We thank R.K.Pritam and L.Biseshwor for their technical assistance.

\section{REFERENCES:}

1. Kearney P M, Whelton M, Reynolds K, Muntner P, Whelton PK, He J. Global burden of hypertension: analysis of worldwide data. Lancet 2005; 365: 217-23.

2. Rodgers A, Lawes C, Mac Mahon S. Reducing the global burden of blood pressure related cardiovascular disease. J Hypertens 2000; 18 (Suppl 1): S3-S6.

3. Ormezzano 0, Cracowski JL, Quesada JL, Pierre H, Mallion JM, Baguet JP. Evaluation of the prognostic value of Baroreflex sensitivity in hypertensive patients: the EVABAR study. J Hypertens. $2008 ; 26(7): 1373-8$.

4. Sesso HD, Wang L, Buring JE, Ridker PM, Gaziano JM. Comparison of Interleukin-6 and C-Reactive Protein for the Risk of Developing Hypertension in Women.Hypertension 2007; 49:304-10.

5. Tatsukwa Y, Hsu WL, Yamada M, Cologne JB, Suzuki G, Yamamoto H, Yamane K, et al. White Blood Cell Count, Especially Neutrophil Count, as a Predictor of Hypertension in a Japanese Population Hypertension Research 2008; 31: 1391-1397 .

6. Woodman RJ, Watts GF, Puddey IB, Burke V, Mori TA, Hodgson JM, Beilin LJ. Leukocyte count and vascular function in type 2 diabetic subjects with treated hypertension. Atherosclerosis. 2002; 163: 175-181

7. Lampert R, Bremmer JD, Su S, Miller A, Lee F, Cheema F, et al. Decrease heart rate variability is associated with higher levels of inflammation in middle-aged men. Am Heart J. 2008; 154(4): 759e 1-7.

8. Psychari SN, Apostolou TS, Iliodromitis EK, Kourakos P, Liakos G, Kremastinos DT. Inverse relation of C-reactive protein levels to heart rate variability in patients after acute myocardial infarction. Hellenic J Cardiol. 2007; 48: 64-71.

9. Sajadieh A, Nielsen OW, Rasmussen V, Hein HO, Abedini S, Hansen JF. Increased heart rate and reduced heart-rate variability are associated with subclinical inflammation in middle-aged and elderly subjects with no apparent heart disease. Eur Heart J.2004; 25: 363-70.

10. Kon H, Nagano M, Tanaka F, Satoh K, Segawa T, Nakamura M. Association of decreased variation of R-R interval and elevated serum C-reactive protein level in a general population in Japan. Int Heart J 2006; 47: 867-876.

11. Borovikova LV, Ivanova S, Zhang M, Yang H, Botchkina GI, Walkins LR, et al. Vagus nerve stimulation attenuates the systemic inflammation response to endotoxin. Nature 2000 ; 405: 458-462. 
12. Marz P, Cheng JG, Gadient RA, Patterson PH, Stovan T, Otten U, et al. Sympathetic neurons can produce and respond to interleukin 6. Proc Nalt Acad Sci USA 1998; 95: 3251-3256.

13. Elencov IJ, Wilder RL, Chroussos GP, Vizi ES. the sympathetic nerve- an integrated interface between two systems: the brain and the immune. Pharmacol Rev 2000; 52: 595-638.

14. Tracey KJ. The inflammatory reflex. Nature 2002; 420: 853-9. (Review)

15. Elvan A, Rubart M, Zipes DP. NO modulates autonomic effects on sinus discharge rate and AV nodal conduction in open-chest dogs. Am J Physiol 1997; H 263-H271.

16. Chowdhary S, Vaile JC, Fetcher J,Ross HF, Coote JH, Townend JN. Nitric oxide and cardiac autonomic control in humans. Hypertension 2000; 36: 264-269.

17. Borman P, Gokoglu F, Kocaoglu S, Yorgancioglu ZR. The autonomic dysfunction in patients with ankylosing spondylitis: clinical and electrophysiological study. Clin Rheumatol 2008; 27(10): 1267-73.

18. Pavithran P, Mithun R, Jomal M, Nandeesha H. Heart rate variability in middle-aged men with new-onset hypertension. Ann Noninvasive Electrocardiol. 2008 ; 13(3):242-8.

19. Neumann SA, Jennings JR, Muldoon MF, Manuck SB. White-coat hypertension and autonomic nervous system dysregulation. Am J Hypertens. 2005 ; 18(5 Pt 1):584-8.

20. Demirci M, Saribas O, Uluc K, Cekirge S, Boke E, Ay H. Carotid artery stenting and endarterectomy have different effects on heart rate variability. J Neurol Sci. 2006; 241: 45-51

21. Head GA. Cardiac baroreflexes and hypertension. Clin Exp Pharmacol Physiol 1994; 21:791-802.

22. Nemes A, Takács R, Gavallér H, Várkonyi TT, Wittmann T, Forster T, et al . Correlations between aortic stiffness and parasympathetic autonomic function in healthy volunteers. Can J Physiol Pharmacol. 2010; 88(12): 1166-71.

23. Suzuki H, Schmid-Schonbein GW, Suematsu M, Delano FA, Forrest MJ, Miyasaka M, et al. Impaired leukocyte-endothelial cell interaction in spontaneously hypertensive rats. Hypertension 1994; 24: 719-727.

24. Walker AE, Seibert SM, Donato AJ, Pierce GL, Seals SR. Vascular endothelial function is related to white blood cell count myleoperoxidase among healthy middle-aged and older adults. Hypertension 2010; 55:363-9. 
Table 1: Comparison of age, BMI, blood pressure, heart rate, HRV, E:I ratio and TLC between the patients with hypertension and the controls.

\begin{tabular}{|l|l|l|}
\hline & Patients with hypertension & Controls \\
\hline Age (years) & $52.00 \pm 11.56$ & $52.00 \pm 11.48$ \\
\hline Height $(\mathrm{cm})$ & $159.89 \pm 8.01$ & $160.52 \pm 9.11$ \\
\hline Weight $(\mathrm{kg})$ & $66.63 \pm 8.73$ & $64.48 \pm 11.71$ \\
\hline BMI $\left(\mathrm{Kg} / \mathrm{m}^{2}\right)$ & $26.44 \pm 3.50$ & $24.95 \pm 3.62$ \\
\hline SBP $(\mathrm{mmHg})$ & $142.94 \pm 7.58$ & $115.71 \pm 7.45$ \\
\hline DBP $(\mathrm{mmHg})$ & $91.65 \pm 5.10$ & $72.34 \pm 8.56$ \\
\hline Resting min HR (bpm) & $73.90 \pm 18.10^{* *}$ & $68.17 \pm 15.68$ \\
\hline Resting max HR (bpm) & $81.50 \pm 19.08$ & $83.80 \pm 13.78$ \\
\hline Resting HRV (bpm) & $7.82 \pm 1.27^{* *}$ & $16.29 \pm 2.05$ \\
\hline E:I ratio & $1.04 \pm 0.11^{*}$ & $1.29 \pm 0.10$ \\
\hline TLC (cells/cumm) & $7476.47 \pm 809.34^{* *}$ & $5224.00 \pm 480.52$ \\
\hline
\end{tabular}

$\mathrm{P}^{*}<0.05 ; \mathrm{P}^{* *}<0.01$; BMI, body mass index; SBP, systolic blood pressure; DBP, diastolic blood pressure; HR, heart rate; min, minimum; max, maximum; bpm, beats per minute; TLC, total leucocyte count; E, expiratory: I, inspiratory.

Table 2: Relation between resting heart rate, resting heart rate variability, E: I ratio and total leucocyte counts in patients with hypertension.

\begin{tabular}{|l|l|l|l|l|}
\hline & $\begin{array}{l}\text { Resting Max } \\
\text { HR }\end{array}$ & $\begin{array}{l}\text { Resting } \\
\text { Min HR }\end{array}$ & $\begin{array}{l}\text { Resting } \\
\text { HRV }\end{array}$ & E:I ratio \\
\hline TLC & -0.153 & -0.010 & $-0.346^{*}$ & $-0.343^{*}$ \\
\hline
\end{tabular}

$\mathrm{P}^{*}<0.05$; HR, heart rate; HRV, heart rate variability; E,expiratory, I, inspiratory. 